\title{
СИНТЕЗ И ИССЛЕДОВАНИЕ СВОЙСТВ НОВЫХ ГИБРИДНЫХ ФОТОХРОМНЫХ ХРОМЕНОВ С ОБРАТИМОЙ МОДУЛЯЦИЕЙ ФЛУОРЕСЦЕНЦИИ
}

\begin{abstract}
А. М. Горелик, О.В. Венидиктова, А. О. Айт, В.А. Барачевский
АЛЕКСАНДР МИХАЙЛОВИЧ ГОРЕЛИК - к.х.н., Центр фотохимии ФНИЦ «Кристаллография и фотоника»PAH. E-mail: 77gorelik@mail.ru.

ОЛЬГА ВЛАДИМИРОВНА ВЕНИДИКТОВА - Центр фотохимии ФНИЦ «Кристаллография и фотоника» PAH.E-mail: wolga.photonics@inbox.ru.

АНТОН ОСКАРОВИЧ АЙТ - к.ф.-м.н., Центр фотохимии ФНИЦ «Кристаллография и фотоника» РАН. E-mail: ao_ait@mail.ru.

ВАЛЕРИЙ АЛЕКСАНДРОВИЧ БАРАЧЕВСКИЙ - к.ф.-м.н., старший научнылй сотрудник, Центр фотохимии ФНИЦ «Кристаллография и фотоника» РАН, ФГБУН Межведомственный иеетр аналитических исследований в области физики, химии и биологии при Президиуме PAH. E-mail: barachevsky@mail.ru.

119421, г. Москва, ул. Новаторов, 7а, к.1, Центр фотохимии ФНИЦ «Кристаллография и фотоника» РАН.

117342, Москва, ул. Профсоюзная, д. 65, стр. 6. Федеральное государственное бюджетное учреждение науки Межведомственный центр аналитических исследований в области физики, химии и биологии при Президиуме Российской академии наук.
\end{abstract}

Исследована реакиия взаимодействия феналенонов, содержащих в пери-положении к карбонильной группе гидроксильную группу с пропаргиловыми спиртами. Синтезировано новое гибридное фотохромное соединение, обладающее фотохромными и люминесцентными свойствами. Проведены спектрально-кинетические исследования полученного соединения и его сравнительный анализ с ранее синтезированными гибридами подобного рода.

Ключевые слова: синтез, спектроскопия, феналенон, фотохром, фотореакция. 


\title{
SYNTHESIS AND INVESTIGATION THE PROPERTIES OF NEW HYBRID PHOTOCHROMIC CHROMENES WITH REVERSIBLE MODULATION OF FLUORESCENCE
}

\author{
A. M. Gorelik ${ }^{1}$, O.V. Venidiktova ${ }^{1}$, A. O. Ayt ${ }^{1}$, V.A. Barachevsky ${ }^{1,2}$ \\ ${ }^{17}$ A Novatorov st., b. 1, Moscow, 119421, Russia. The Photochemistry center of the Russian academy of sciences \\ (PC RAS). \\ ${ }^{2} 65$ Profsoyuznaya Street, Moscow, 117342, Russia; Interdepartmental Center for Analytical Research in Physics, \\ Chemistry, and Biology, Presidium RAS.
}

The reaction between phenalenon derivatives with hydroxygroup in pery-posithion to carbonyl and propynole has been investigate. The new hybrid compound has been synthesized and spectral-kinetic properties measured. This compound has photochromic and fluorescent properties in one time.

Keywords: synthesis, spectroscopy, phenalenon, photochromic compounds, photoreaction.

\section{Введение}

Фотохромные органические соединения привлекают значительный интерес, поскольку на их основе возможно создание различных устройств и материалов, меняющих свои свойства под действием света. Так, на основе органических фотохромов производят линзы для солнцезащитных очков, красители для денежных знаков, оптические метки [1-3]. Развитие данного направления имеет значение и для разработки оптических устройств записи, считывания и хранения информации, лекарственных препаратов с фотоуправляемой фармакологической активностью, а также нелинейных оптических устройств $[4,5]$.

\section{Экспериментальная часть}

Наиболее перспективными фотохромными соединениями являются бензо- и нафтопираны (хромены) поскольку они, в первую очередь, обладают большей фотохимической стабильностью по сравнению с другими классами органических фотохромов, таких как, например, спиропираны и спирооксазины. В циклической (закрытой) форме они бесцветны, но под действием УФ излучения или солнечного света происходит разрыв С-О связи пиранового кольца в результате чего образуется окрашенная мероцианиновая форма молекулы, способная к обратимому фотоиндуцированному или термическому изменению спектральных характеристик.
Получение гибридных соединений, содержащих в молекуле нафтопирановый фрагмент, способный к фотохромным превращениям, и фрагмент перинафтенона, обладающий люминесцентными свойствами позволяет влиять на флуоресценцию посредством фотохромных превращений в молекуле. Подобная фотоиндуцированная модуляция флуоресценции могла бы привести к созданию оптических переключателей с высокой светочувствительностью.

Спектральные и кинетические свойства соединений в большой степени зависят от природы заместителей и их взаимной конфигурации. Нами ранее были синтезированы четыре гибридных соединения, исходя из 3-метил-6-гидроксиперинафтенона 1a обладающего люминесцирующими свойствами в качестве субстрата и различных 1,1-диарил-2пропин-1-олов [6].

В данной работе изучена возможность получения двух новых гибридных соединений, исходя из перинафтенонов - 3-метил-6-метокси-9-гидроксифенален-1-она $\mathbf{1 b}$ и 3-метил-6,9-дигидроксифенален-1-она 1c содержащих в пери-положении к кетогруппе свободную гидроксильную группу (Схема 1).

В реакции конденсации получения бензои нафтохроменов чаще всего используется в качестве катализатора $n$-толуолсульфокислота. В случае получения люминесцирующих фотохромов нами были использованы иные, более эффективные катализаторы, такие как пиридиний $n$-толуолсульфонат (PPTS) либо пиридиний 


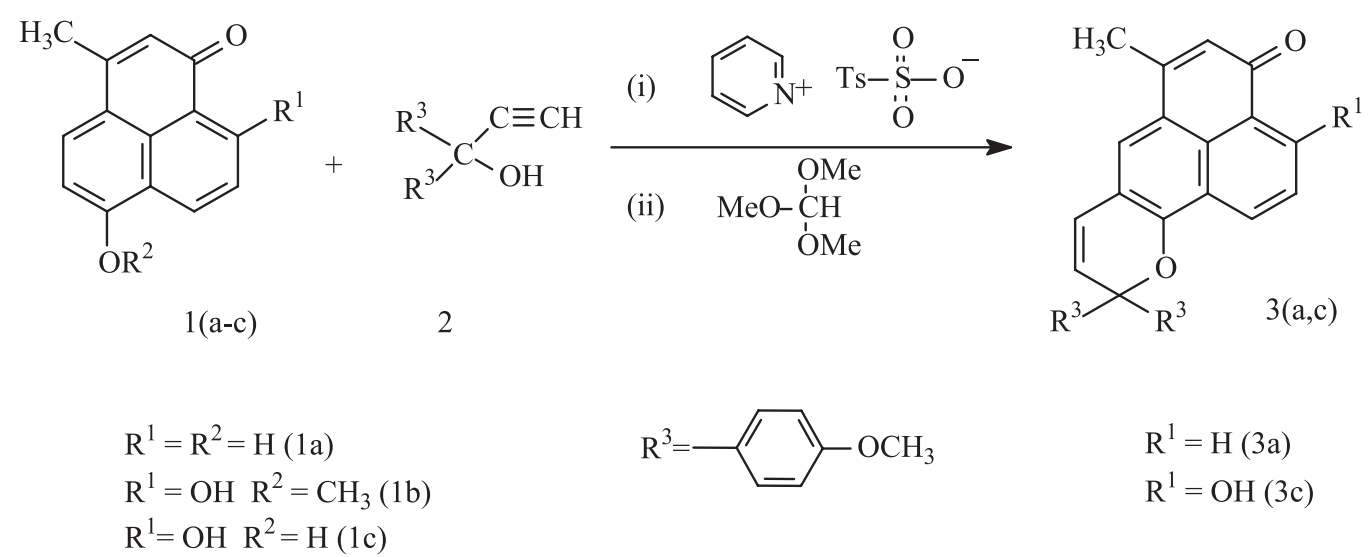

Схема 1. Синтез хромена 3c

$n$-трифторметилсульфонат (PTFS) в присутствии в качестве водоотнимающего средства триметилортоформиата (ТМР). Для повышения эффективности взаимодействия реагентов раствор компонентов в дихлорэтане предварительно помещали в ультразвуковую ванну для диспергирования.

Как и предполагалось, возможность образования пиранового цикла с участием кислорода гидроксильной группы в положении 9 для соединения $\mathbf{1 b}$ не реализуется, поскольку этому мешает затрудненность элиминирования водорода ввиду включения его в шестичленный цикл с сильной водородной связью между протоном гидроксильной группы и карбонилом. (Смещение сигнала протона 9-ОН в спектре ПМР достигает значений $\delta=13-14$ м.д.). Кроме того, положение 8 перинафтенона малоактивно к электрофильному замещению.

В то же время, соединение 1с активно взаимодействует с пропаргиловым спиртом $\mathbf{2}$ с образованием 6-метил-3-гидрокси-10-бис(4метоксифенил)-10Н-11-оксо-бензо[dе]антрацен4-она 3c. После хроматографической очистки нами выделен продукт, выход которого составляет $23 \%$. Структура полученного соединения подтверждена данными спектров ПМР и массспектром (m/z $\left.475[\mathrm{M}]^{+}\right)$. 6-Метил-10,10-ди(4-
метоксифенил)-10Н-11-оксо-бензо[dе]антрацен-4он (3a) получен нами ранее [6].

3-Метил-6,9-дигидроксифенален-1-он 1с был получен по методике конденсации Пехмана - взаимодействием 1,6-диметоксинафталина 4 с ацетоуксусным эфиром 5 в полифосфорной кислоте с последующим деметилированием диметилового эфира феналенона при нагревании в бромистоводородной кислоте. 3-Метил-6-метокси-9-гидроксифенален-1он $\mathbf{1 b}$ выделен как продукт неполного деметилирования 3-метил-6,9-диметоксифеналенона при этом же взаимодействии (Схема 2).

1,1-Ди(4-диметоксифенил)-2-пропин-1-ол 2 получен по модифицированной нами методике [7] при взаимодействии 4,4'-диметоксибензофенона и этилендиаминового комплекса ацетилида лития в безводном диметилсульфоксиде.

Спектрофотометрические измерения растворов соединения $\mathbf{3 c}$ в толуоле проводили на спектрофотометре «Cary-60 UV-Vis» («Agilent Technologies») и спектрофлуориметре «CARY Eclipse» при облучении светом ксеноновой лампы LC-4 фирмы «Hamamatsu».

Соединение 3c, как и ранее описанные гибридные соединения [6], проявляет фотохромные свойства (схема 3), что отражается, как в спектрах поглощения, так и в спектрах люминесцен-<smiles>CCOc1cccc2cc(OC)ccc12</smiles>

Схема 2. Получение феналенона 1c 
ции (рис. 1). Исходная циклическая форма $\mathbf{A}$ характеризуется, как и подобные хромены [6], полосами поглощения в УФ и видимой области спектра 250-500 нм (рис. 1, кр. 1). При УФ облучении появляется фотоиндуцированная окрашенная форма $\mathbf{B}$, проявляющая полосу поглощения в длинноволновом спектральном диапазоне с максимумом при 576 нм (рис. 1, кр. 2). Спонтанное превращение фотоиндуцированной формы в исходное циклическое соединение характеризуется константой скорости $\mathrm{k}=0,014 \mathrm{c}^{-1}$.<smiles></smiles>

A<smiles>[R]C([R])=CC=c1cc2c(C)cc(=O)c3c(O)ccc(c3-2)c1=O</smiles>

B
Схема 3. Фотохромные превращения хромена $3 \mathrm{c}$

Из рис. 1 видно, что гидрокси-замещенный хромен характеризуется умеренными фотохромными превращениями (рис. 1, кр. 1, 2 и 3), которые уступают по эффективности фотохромным превращениям ранее синтезированным соединениям этого типа, в частности незамещенному хромену 3a [6].

Исследование цикличности процессов фотоокрашивания и фотообесцвечивания соединения

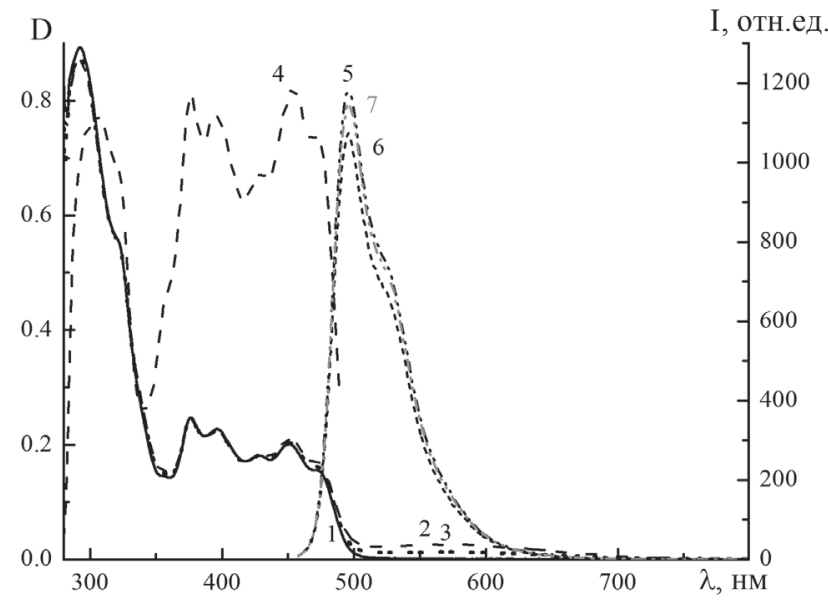

Рис. 1. Спектры поглощения (кр. 1-3), возбуждения флуоресценции при измерении на длине волны 499 нм (кр. 4) и флуоресценции при возбуждении светом с длиной волны 452 нм (кр. 5-7) соединения GV-07 в толуоле до $(\kappa p . ~ 1,4,5)$, после облучения через УФС-1 (кр. 2, 6) и темновой релаксации $(\kappa р .3,7)$
$3 \mathbf{c}$ в толуоле подтвердило, что данный класс фотохромных соединений характеризуется высокой цикличностью (рис. 2), причем наибольшее количество циклов наблюдается для гибридного хромена 3c содержащего гидроксильную группу.

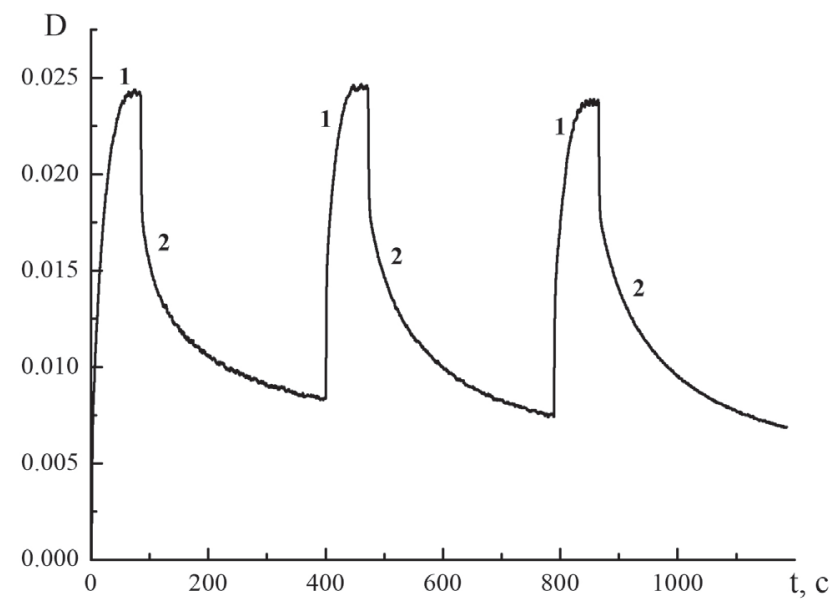

Рис. 2. Кинетические кривые циклических процессов фотоокрашивания (1) и фотообесцвечивания (2) соединения $3 \mathrm{c}$ в толуоле, зарегистрированные на длине волны 570 нм

Исходная циклическая форма хромена $\mathbf{3 c}$ проявляет флуоресценцию с максимумом полосы при 495 нм (рис. 1, кр. 5). Принадлежность наблюдаемой флуоресценции этой форме подтверждается совпадением спектров поглощения и возбуждения флуоресценции (рис. 1, кр. 4).

Следует отметить, что полосы флуоресценции исходной циклической формы А и поглощения фотоиндуцированной окрашенной формы В перекрываются.

В процессе фотохромных превращений наблюдается модуляция интенсивности флуоресценции (рис. 1 , кр. $5,6,7)$. Интенсивность люминесценции падает после появления фотоиндуцированной окрашенной формы и восстанавливается при отключении активирующего УФ излучения. Как и в случае аналогов этого хромена [6], модуляцию интенсивности флуоресценции можно объяснить, как фотоиндуцированным изменением концентрации флуоресцирующих молекул, так и фотоиндуцированным индуктивно-резонансным переносом энергии возбуждения от флуоресцирующих исходных молекул к фотоиндуцированным окрашенным молекулам.

Проведенные квантово-химические расчеты подтверждают полученные экспериментальные данные. 


\section{Выводы}

Таким образом, в результате выполненного исследования синтезировано новое гидроксил-замещенное гибридное соединение $\mathbf{3 c}$, содержащие в молекуле бензопирановый и перинафтеновый фрагмент. Как и ранее исследованные соединения [6], гибридный хромен 3c проявляет фотохромные превращения, а также флуоресцентные свойства исходной хроменовой формы. Предварительные данные позволяют утверждать, что соединение 3c с гидроксильной группой в положении 3 (соединение 3c) является более фотохимически стабильным в отличие от других аналогичных соединений. Фотохромные превращения этого класса соединений обуславливают модуляцию флуоресценции. Полученные результаты свидетельствуют о возможности создания на основе подобных гибридных соединений флуоресцентных фотопереключателей.

Работа выполнена при поддержке Министерства науки и высшего образования Российской Федераиии в рамках выполнения работ по Государствен- ному заданию ФНИЦ «Кристаллография и фотоника» РАН.

\section{Лuтература}

1. Gemert V.B. NewYork, PlenumPresss. 1999. V. 1. P. 111-141.

2. Crano J., Flood T., Knowles A., Kumar A., Van Gemert B. Pure and Applied Chemistry. 1996. V. 68. P. 1395-1398.

3. Evans R.A., Hanley T.L., Skidmore M.A. Nature Materials. 2005. V. 4. P. 249-253.

4. Berkovic G., Krongauz V., Weiss V. Cemical. Revies. 2000. V. 100. №5. P. 1741-1753.

5. Delaire J., Nakatani K. Chemical Reviews. 2000. V. 100. № 5. P. 1817-1845.

6. Горелик А.М., Венидиктова О.В., Айт А.О., Барачевский В.A. Фотохромные гибридные соединения с фотоиндуцированной модуляцией флуоресценции. Материалы 13 Всероссийской научной конференции «Технологии и материалы для экстремальных условий (прогнозные исследования и инновационные разработки)», Изд. МЦАИ РАН. 2018. С. 28-34.

7. Hepworth J.D., Heron B.M. Photochromic naphthopyrans, Functional Dyes, Chapter 3, Elsevier B.V. 2006. P. 90. 